\title{
Numerical investigation of the ventilation performance of a solar chimney
}

\author{
$\begin{array}{lll}\text { R. Khanal } & \text { C. } \text { Lei }^{2}\end{array}$
}

(Received 30 January 2011; revised 19 October 2011)

\begin{abstract}
This article reports a two dimensional, steady state, numerical simulation of the air flow inside a solar chimney with a fixed absorber height but various air gap widths and inlet aperture heights. The ventilation performance of the solar chimney in terms of the mass flow rate is presented. The numerical results show that the mass flow rate is an increasing function of surface emissivity and input heat flux. It is also found that the mass flow rate is up to $59 \%$ higher with a surface emissivity of 0.9 than that with a zero surface emissivity. This investigation shows the importance of radiation heat transfer in a solar chimney system. The numerical results further show that the ventilation performance of the solar chimney is more sensitive to the change in the air gap width than to the change in the inlet aperture height, and an optimum inlet aperture height can be identified.
\end{abstract}

http://journal . austms.org.au/ojs/index.php/ANZIAMJ/article/view/3947 gives this article, (c) Austral. Mathematical Soc. 2011. Published October 24, 2011. ISSN 1446-8735. (Print two pages per sheet of paper.) Copies of this article must not be made otherwise available on the internet; instead link directly to this URL for this article. 


\section{Contents}

1 Introduction

C900

2 Solar chimney model

C902

3 Problem formulation

C903

4 Numerical solution details

C904

5 Results and discussion

C905

6 Conclusion

C911

References

C911

\section{Introduction}

A solar chimney is an excellent passive ventilation device which relies on a natural driving force, the energy from the sun, and is designed to maximise the ventilation performance by maximising the solar gain [5]. The basic driving mechanism of the air flow inside a solar chimney is thermal buoyancy. The thermal buoyancy is caused by the density variation of the fluid (air) due to the temperature difference between the inside and outside of the building, and within different sections of the building.

The pioneering work on solar chimney performance was carried out by Bansal et al. [5], who proposed an expression for the volume flow rate of air by solving the energy balance and continuity equations. A number of experimental investigations of a solar chimney were reported subsequently. To name only a few, Arce et al. [2] and Afonso and Oliveira [1] studied the ventilation performance of a full scale model of a solar chimney under realistic conditions, whereas Chen et al. [8] and later Burek and Habeb [7] considered large scale 
models under a controlled laboratory environment. Similarly, Mathur et al. [4] studied a window sized, small scale model under realistic conditions. Among the numerical studies, Moshfeg and Sandberg [14] considered conjugate heat transfer by convection and radiation for a 6.5 metre tall solar chimney with various aspect ratios, and revealed the importance of surface radiation on fluid flow inside the air channel. In contrast to Bacharoudis et al. [3], Zamora and Kaiser [18] and others who modelled a solar chimney with a uniform wall temperature, Sandberg and Moshfeg [14] modelled the solar chimney with one wall adiabatic and the other with a uniform heat flux. We believe the latter modelling strategy is a better representation of reality and hence we adopt similar thermal boundary conditions in the present study.

Many researchers identified the importance of the air gap width on the ventilation performance of a solar chimney. However, Lee and Strand [11] identified the air gap width as the parameter with the least influence on ventilation performance in terms of mass flow rate. Similarly, Miyazaki et al. [13] reported that for a solar chimney with an air gap width more than $0.2 \mathrm{~m}$, the mass flow rate is independent of the chimney air gap width. All these works contributed to our present understanding of the subject. However, the contradictory results reported suggest that the solar chimney as a ventilation strategy is not fully understood and thus needs further investigation. This is the motivation behind the present work. Moreover, very few numerical investigations have focused on small scale solar chimneys with absorber height less than $1 \mathrm{~m}$.

The present work deals with numerical simulation of natural convection flow inside a solar chimney. Both convection and radiation heat transfer are considered as the mechanisms through which thermal energy is transferred within the solar chimney. The problem outlined has practical applications in building ventilation as well as theoretical appeal to understanding the complex thermo-fluid phenomena inside the solar chimney. 


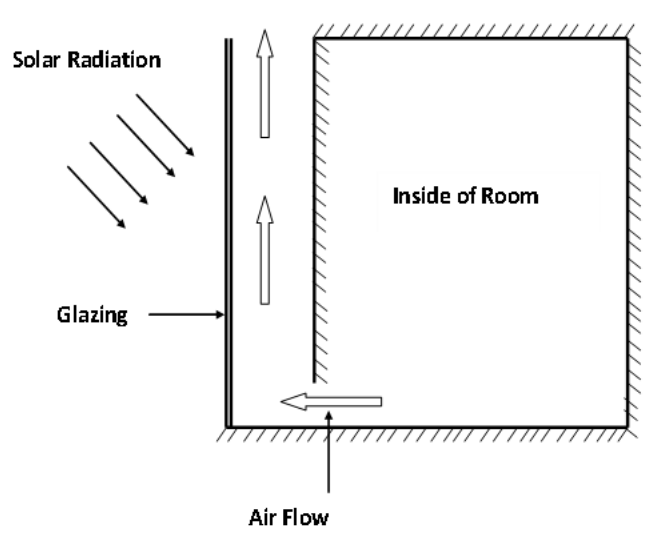

(a)

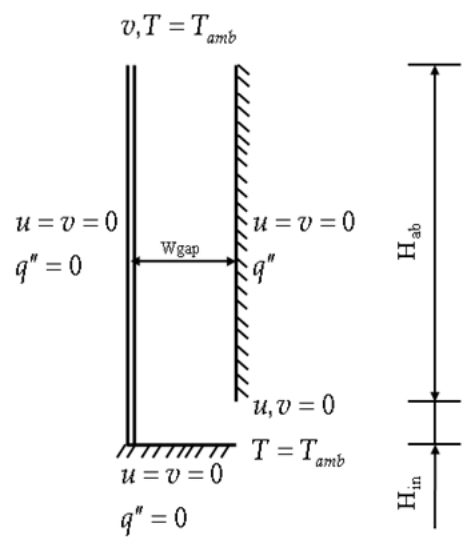

(b)

Figure 1: (a) Schematic diagram of a two dimensional solar chimney attached to a room. (b) A truncated two dimensional solar chimney model with boundary conditions adopted in this study.

\section{Solar chimney model}

A typical two dimensional representation of the physical system of a solar chimney is depicted in Figure 1. The horizontal distance between the glazing and the absorber wall is referred to as the air gap width, $W_{\text {gap }}$. In this study, the absorber height, $\mathrm{H}_{\mathrm{ab}}$, is fixed $(0.7 \mathrm{~m})$ but the inlet aperture height, $\mathrm{H}_{\mathrm{in}}$, is variable, giving rise to different solar chimney heights. The typical ranges of parameters considered in this study are $0.1-0.4 \mathrm{~m}$ for the air gap width and $0.1-0.5 \mathrm{~m}$ for the inlet aperture height, respectively. The other important governing parameters are the Rayleigh and Prandtl numbers,

$$
\mathrm{Ra}=\frac{g \beta q^{\prime \prime} \mathrm{H}_{\mathrm{ab}}^{4}}{\alpha v k} \text { and } \operatorname{Pr}=\frac{v}{\alpha},
$$


where $\beta$ is the coefficient of thermal expansion, $v$ is the kinematic viscosity, $\alpha$ is the thermal diffusivity, $k$ is the thermal conductivity, and $q^{\prime \prime}$ is the input heat flux. SI units are adopted throughout.

\section{Problem formulation}

We expect that the temperature variation from the inlet to the exit of the solar chimney is not very large, and thus the Boussinesq approximation is adopted. Under this assumption, we solve simplified Navier-Stokes equations for a two dimensional Newtonian incompressible flow. As the governing equations are available in almost every numerical article on the subject and also in standard textbooks, they are not presented here. For the radiation formulation, we assume that the channel wall surfaces are diffuse and grey. The radiative heat exchange between surface elements is then calculated from the relation [17]

$$
\sum_{j=1}^{N}\left[\delta_{i j}-\left(1-\epsilon_{j}\right) F_{i-j}\right] \frac{q_{r, j}}{\epsilon_{j}}=\sum_{j=1}^{N}\left(\delta_{i j}-F_{i-j}\right) \sigma T_{j}^{4},
$$

where $i$ and $j$ index the $N$ surface elements, $\delta_{i j}$ is the Kronecker delta, $\epsilon_{j}$ is the surface emissivity, $F_{i-j}$ is the configuration factor, $q_{r, j}$ is the radiative heat flux, and $\sigma$ is the Stefan-Boltzmann constant.

Assuming $\mathrm{q}^{\prime \prime}=100 \mathrm{~W} / \mathrm{m}^{2}$ and $\mathrm{H}_{\mathrm{ab}}=0.7 \mathrm{~m}$, Equation (1) gives Rayleigh number $\mathrm{Ra}=8.36 \times 10^{10}$. For the case of natural convection adjacent to a vertical, isothermally heated, flat plate, such a high value of the Rayleigh number might suggest the flow is turbulent. However, Chen et al. [8] reported that, for natural convection adjacent to a vertical flat plate heated by a uniform heat flux, the transition to turbulence occurs at $\mathrm{Ra}>2 \times 10^{13}$. Bejan [6] considered a similar range of Rayleigh numbers based on a constant heat flux for laminar flows. We therefore model the flow as laminar. 


\section{$4 \quad$ Numerical solution details}

Results presented in this work are obtained numerically using the commercial CFD package ANSYS-FLUENT 12.0, which is based on a control volume method. The governing equations are solved on a staggered grid and the coupling between the momentum and continuity equations through pressure is based on the SIMPLE (Semi Implicit Pressure Linked Equation) scheme [15]. The second order, upwind, differencing scheme is applied for convective terms of the momentum and energy transport equations, whereas pressure is descretized using the PRESTO (Pressure Staggering Option) scheme [9]. To ensure numerical stability, the discretized equations are solved by iteration with under-relaxation factors of 0.3 for pressure, 0.7 for momentum and 1 for density, body force and energy. Solution convergence is controlled by setting the convergence criterion (residual) to $10^{-5}$ for each equation except for the energy equation, which is set to $10^{-6}$. All results reported in this article are obtained using a double precision solver.

Two dimensional quadrilateral elements are employed to create a non-uniform structured mesh using ANSYS Workbench. In order to ensure the accuracy of the numerical results, a grid dependence study is performed with three different meshes: $100 \times 36,200 \times 72$ and $400 \times 144$. Based on this numerical test, the medium mesh of $200 \times 72$ elements is adopted in this study, as it provides sufficient spatial resolution for a grid independent solution with much less computing time than the finest mesh.

Validation of our numerical procedure for the solar chimney model is carried out by comparing the present numerical data, obtained for a solar chimney with vertical inlet, to the experimental data obtained for a 1.5-metre tall solar chimney [8]. Figure 2 shows the comparison between the experimental and numerical air flow rates obtained for a $200 \mathrm{~mm}$ air gap width at 200, 300, 400,500 and $600 \mathrm{~W} / \mathrm{m}^{2}$ input heat fluxes, respectively. The figure shows a clear agreement between the experimental and numerical data, confirming an increase in the air flow rate with an increase in the input heat flux. All 


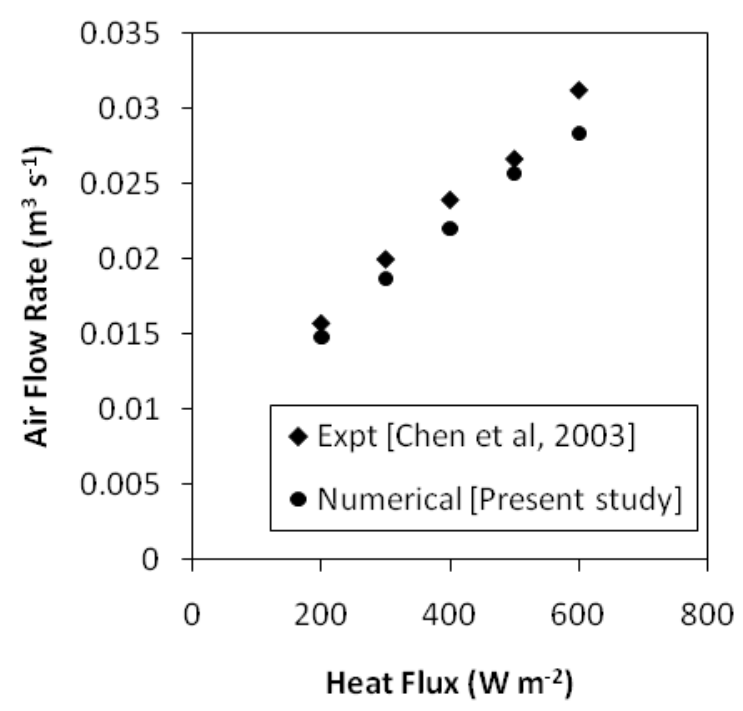

Figure 2: Comparison between experimental and numerical air flow rates through a $1.5 \mathrm{~m}$ high chimney with a $0.2 \mathrm{~m}$ air gap width for various heat inputs.

the numerical results reported in Figure 2 are well within the experimental uncertainty of the air velocity measurements reported by Chen et al. [8]. However, the predicted air flow rate is consistently lower than the experimental results. This discrepancy between the experimental and numerical results could be attributed to the computational domain effect [10].

\section{Results and discussion}

Figures 3 and 4 show the predicted mass flow rates for different air gap widths and inlet aperture heights for a case with zero surface emissivity. The lines in these figures, as well as in Figure 5, are piece-wise linear interpolants. Figure 3 shows a small increment in the mass flow rate with the increase of the inlet 


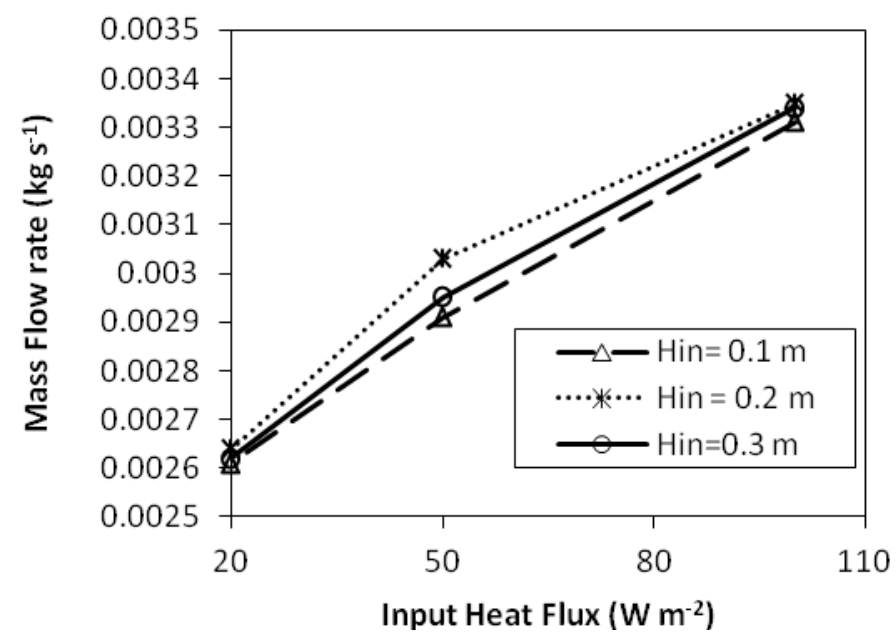

Figure 3: Predicted mass flow rate at various input heat flux for a $0.1 \mathrm{~m}$ air gap width with various inlet aperture heights.

aperture height from $0.1 \mathrm{~m}$ to $0.2 \mathrm{~m}$, and further increase of the inlet aperture height results in a decrease of the mass flow rate. This is attributed to the reduction of the flow kinetic energy with the increase of the inlet aperture height.

Figure 4 shows the predicted mass flow rate at different air gap widths with a given inlet aperture height for different input heat flux. The figure indicates that as the chimney air gap width increases for a fixed inlet aperture height, the mass flow rate decreases. This is be attributed to the decrease of the flow kinetic energy with the increase in the chimney cross-section area. Furthermore, with the increase in the air gap width, a reverse flow occurs at the chimney exit; as seen in Figure 6(c). We are currently investigating this reverse flow and its impact on the ventilation performance, and will report separately.

Figures 3 and 4 indicate that the mass flow rate is more sensitive to the change in the air gap width than to changes in the inlet aperture height. A 


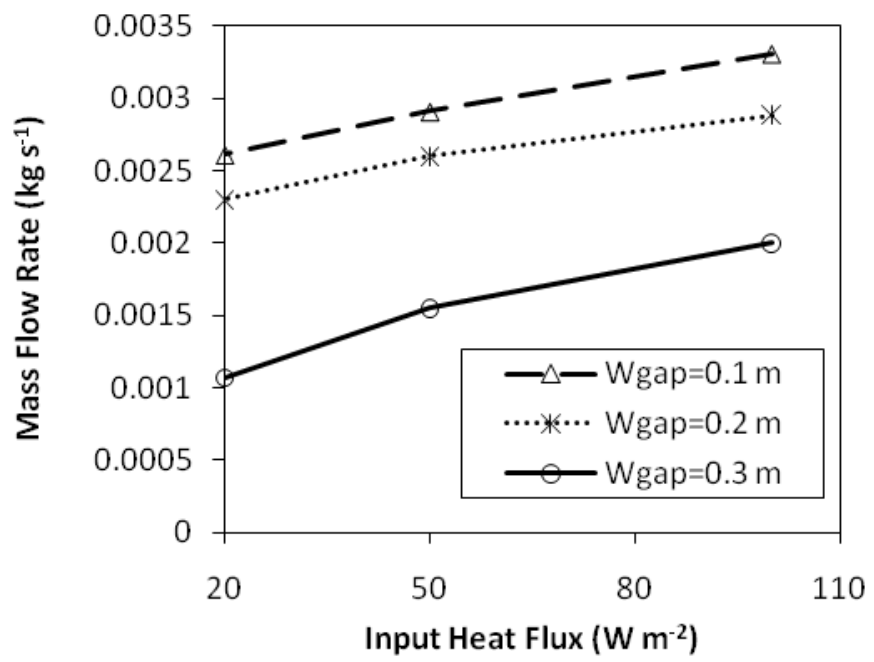

Figure 4: Predicted mass flow rate at various input heat flux at an inlet aperture height of $0.1 \mathrm{~m}$ for various air gap widths.

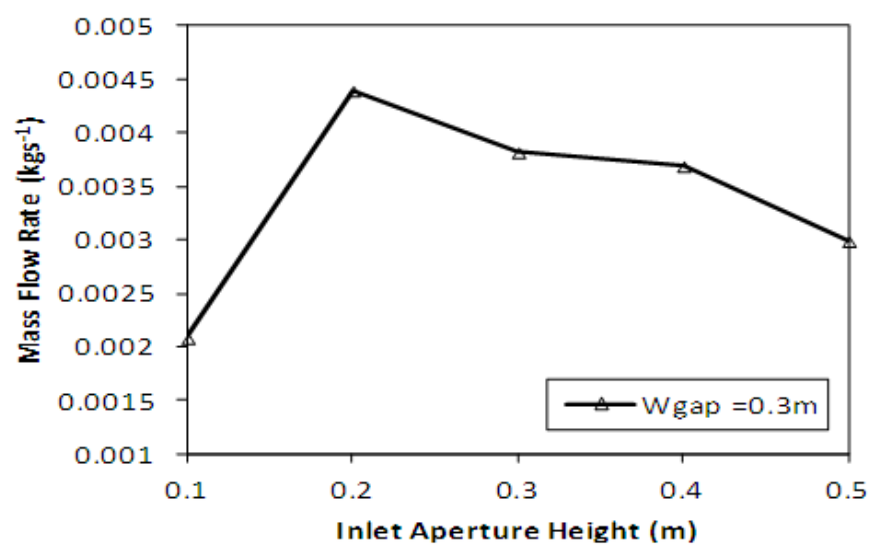

Figure 5: Predicted mass flow rate at input heat flux of $100 \mathrm{~W} / \mathrm{m}^{2}$ and an air gap width of $0.3 \mathrm{~m}$ for various inlet aperture heights for the case with zero surface emissivity. 
typical case, with an absorber height of $0.7 \mathrm{~m}$ and an air gap width of $0.3 \mathrm{~m}$, is now considered. The mass flow rate is calculated for a fixed input heat flux $\left(100 \mathrm{~W} / \mathrm{m}^{2}\right)$ and various inlet aperture sizes $(0.1-0.5 \mathrm{~m})$, and the results are presented in Figure 5. The figure clearly shows improvement in the mass flow rate up to a certain value of the inlet aperture height, after which further increase in the inlet aperture height does not have any positive effect on improving the mass flow rate. This result indicates that, based on the range of the tests $(0.1-0.5 \mathrm{~m})$, there is an optimum value of the inlet aperture height.

In Figure 6, (a) and (c) show the isotherms and streamlines, respectively, for a selected case without surface emissivity. This behaviour changes to that shown in (b) and (d) when surface emissivity is present. It is evident from the figure that the thermal flow structure changes with the presence of radiation heat exchange. Figure 6(a) shows that a thermal boundary layer is formed adjacent to the heated wall only, whereas in Figure 6(b) thermal boundary layers are formed adjacent to both walls. The thermal boundary layer adjacent to the unheated wall is due to radiation heat exchange between the two vertical surfaces of the solar chimney. Radiation heat exchange increases the mass flow rate through the chimney as more fluid is driven by the buoyancy force in the region close to the walls in the thermal boundary layer. Outside the thermal boundary layer, fluid is mainly driven by the pressure gradient resulting from the inlet pressure boundary condition [12].

Figure 6(c) shows a reverse flow at the exit of the solar chimney for the case with zero emissivity. The reverse flow is due to thermal boundary layer entrainment of fresh air from the exterior of the solar chimney in order to satisfy conservation of mass. The detailed mechanism of the boundary layer entrainment needs to be further investigated. For the case with an emissivity value of 0.9 , Figure $6(\mathrm{~d})$ shows no reverse flow at the exit of the chimney. However, a small circulation can be seen in the region near to the leading edge of the thermal boundary layer, just above the inlet aperture at the heated wall. This is attributed to the separation of the inlet flow at the leading edge. With the radiation effect, the inlet flow is stronger, and thus separation is more likely. 


$$
\varepsilon=0 \quad \varepsilon=0.9
$$

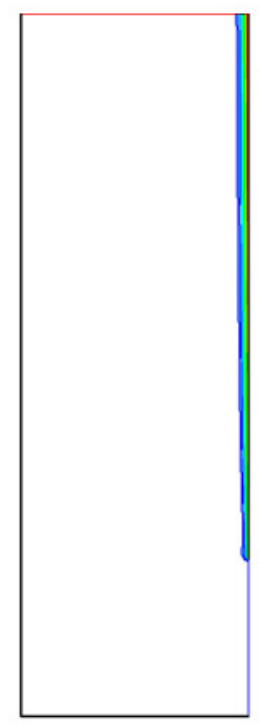

\section{(a)}

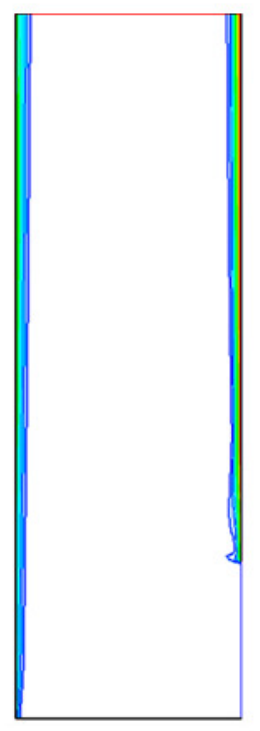

(b) $\varepsilon=0$

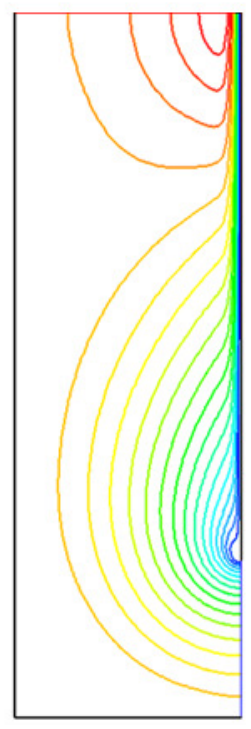

(c) $\varepsilon=0.9$

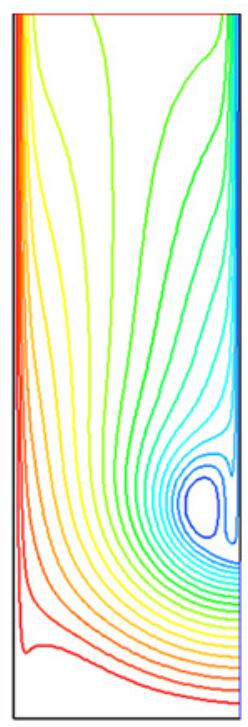

(d)

Figure 6: Contours of static temperature (a) and (c) and stream lines (c) and (d) for air gap width $0.3 \mathrm{~m}$, inlet aperture height $0.2 \mathrm{~m}$ and absorber height $0.7 \mathrm{~m}$. In each pair of figures, the case without radiation transfer is on the left and the case with radiation transfer is on the right. For both cases, $\mathrm{Ra}=8.36 \times 10^{10}$.

Figure 7 shows the effect of surface emissivity on the ventilation performance in terms of mass flow rate. Here the surface emissivity is considered for both walls (the heated and insulated walls). In one case, the surface emissivity is assumed to be 0.9 for both bounding walls. In the other case, the surface emissivity is assumed to be zero for both bounding walls, indicating no radiation heat exchange between the two bounding walls. 


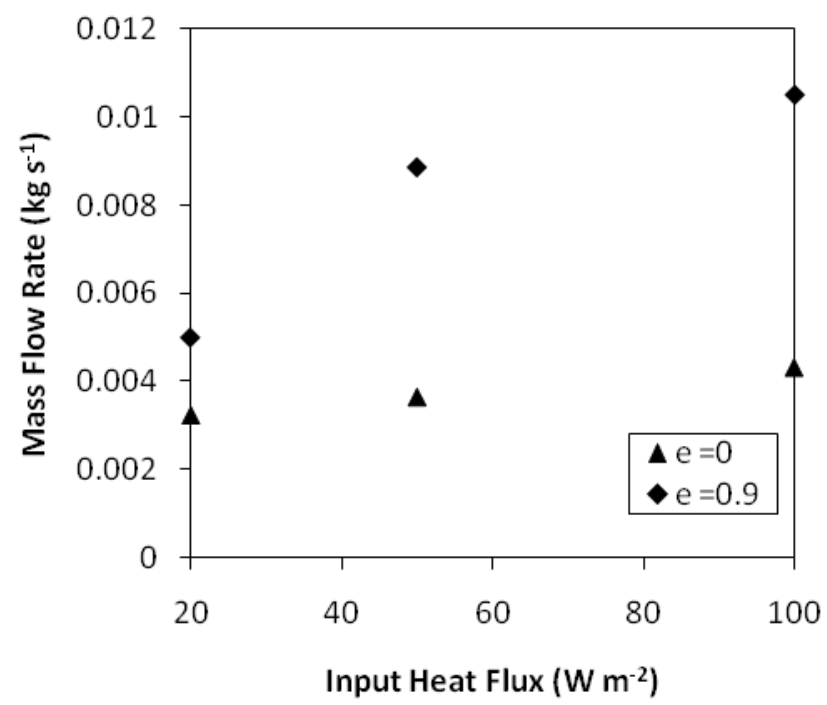

Figure 7: Effect of surface emissivity on the mass flow rate at various input heat flux for the chimney with a $0.7 \mathrm{~m}$ absorber height, a $0.3 \mathrm{~m}$ air gap width and a $0.2 \mathrm{~m}$ inlet aperture height.

Figure 7 shows that the surface radiation has a positive effect on the mass flow rate enhancement, and the mass flow rate is an increasing function of emissivity and input heat flux. At an input heat flux of $100 \mathrm{~W} / \mathrm{m}^{2}$, the predicted mass flow rate with a surface emissivity of 0.9 is $59 \%$ higher than that predicted with a zero emissivity. This result indicates that, in a solar chimney system, radiation heat transfer plays a significant role in ventilation performance in terms of mass flow rate, and thus should not be ignored. Radiation heat transfer increases the temperature of the insulated wall. Moshfeg and Sandberg [16] showed that about $40 \%$ of the input heat could be transferred to the insulated wall via radiative heat transfer, whereas Chen et al. [8] estimated it to be less than $10 \%$ of the input heat. This heat transfer decreases with the input heat flux, and so does the mass flow rate (refer to Figure 7). 


\section{Conclusion}

Almost all solar chimney studies are aimed at finding optimum design solutions for enhancing natural ventilation, taking into consideration different design parameters. We considered the inlet aperture height, air gap width and surface emissivity to study the ventilation performance of a small solar chimney in terms of mass flow rate. Our study shows that the mass flow through a solar chimney is more sensitive to changes in the air gap width than to changes in the inlet aperture height. The present results also show the existence of an optimum inlet aperture height. Without considering the radiation heat exchange, a reverse flow is observed at the chimney outlet even for a small air gap width. This needs to be further investigated. Surface emissivity is found to have a positive effect on the mass flow rate, and hence radiation heat exchange should not be ignored in solar chimney systems.

\section{References}

[1] C. Afonso and A. Oliveira. Solar chimneys: simulation and experiment. Energy and Buildings, 32:71-79, 2000. doi:10.1016/S0378-7788(99)00038-9. C900

[2] J. Arce, M. J. Jiminez, G. Alvarez J. D. Guzmán, M. R. Heras, and J. Xamán. Experimental study for natural ventilation on a solar chimney. Renewable Energy, 34:2928-2934, 2009. doi:10.1016/j.renene.2009.04.026. C900

[3] E. Bacharoudis, M. G. Vrachopoulos, D. Margaris M. K. Koukou, A. E. Filios, and S. A. Mavrommatis. Study of the natural convection phenomena inside a wall solar chimney with one wall adiabatic and one wall under a heat flux. Applied Thermal Engineering, 27:2266-2275, 2007. doi:10.1016/j.applthermaleng.2007.01.021. C901 
[4] N. K. Bansal, J. Mathur, S. Mathur, and M. Jain. Modeling of window-sized solar chimneys for ventilation. Building and Environment, 40:1302-1308, 2005. doi:10.1016/j.buildenv.2004.10.011. C901

[5] N. K. Bansal, R. Mathur, and M. S. Bhandari. Solar chimney for enhanced stack ventilation. Building and Environment, 28:373-377, 1993. doi:10.1016/0360-1323(93)90042-2. C900

[6] A. Bejan. Heat Transfer. John Wiley and Sons, Inc., 1993. C903

[7] S. A. M. Burek and A. Habeb. Air flow and thermal efficiency characteristics in solar chimneys and trombe walls. Energy and Buildings, 39:128-135, 2007. doi:10.1016/j.enbuild.2006.04.015. C900

[8] Z. D. Chen, P. Bandopadhayay, J. Halldorsson, C. Byrjalsen, P. Heiselberg, and Y. Li. An experimental investigation of a solar chimney model with uniform wall heat flux. Building and Environment, 38:893-906, 2003. doi:10.1016/S0360-1323(03)00057-X. C900, C903, C904, C905, C910

[9] Fluent Incorporated. Fluent User's Guide, 2006. C904

[10] G. Gan. Impact of computational domain on the prediction of buoyancy-driven ventilation cooling. Building and Environment, 45:1173-1183, 2010. doi:10.1016/j.buildenv.2009.10.023. C905

[11] K. H. Lee and R. K. Strand. Enhancement of natural ventilation in buildings using a thermal chimney. Energy and Buildings, 41:615-621, 2009. doi:10.1016/j.enbuild.2008.12.006. C901

[12] F. Marcondes and C. Maliska. Treatment of the inlet boundary conditions in natural-convection flows in open-ended channels. Numerical Heat Transfer, Part B: Fundamentals, 35:317-345, 1999. doi:10.1080/104077999275893. C908

[13] T. Miyazaki, A. Akisawa, and T. Kashiwagi. The effects of solar chimneys on thermal load mitigation of office buildings under the 
Japanese climate. Renewable Energy, 31:987-1010, 2006. doi:10.1016/j.renene.2005.05.003. C901

[14] B. Moshfegh and M. Sandberg. Investigation of fluid flow and heat transfer in a vertical channel heated from one side by PV elements, Part I-Numerical study. Renewable Energy, 8:248-253, 1996. doi:10.1016/0960-1481(96)88856-2. C901

[15] S. V. Patankar. Numerical Heat Transfer and Fluid Flow. Hemisphere Publishing Corporation, New York, 1980. C904

[16] M. Sandberg and B. Moshfegh. Investigation of fluid flow and heat transfer in a vertical channel heated from one side by PV elements, Part II-Experimental study. Renewable Energy, 8:254-258, 1996. doi:10.1016/0960-1481(96)88857-4. C910

[17] R. Siegel and J. R. Howell. Thermal Radiation Heat Transfer. Hemisphere Publishing Corporation, Washington, 1981. C903

[18] B. Zamora and A. S. Kaiser. Thermal and dynamics optimization of the convective flow in Trombe wall shaped channels by numerical investigation. Heat and Mass Transfer, 45:1393-1407, 2009. doi:10.1007/s00231-009-0509-6. C901

\section{Author addresses}

1. R. Khanal, School of Civil Engineering, The University of Sydney, NSW 2006, Australia.

mailto:r.khanal@sydney.edu.au

2. C. Lei, School of Civil Engineering, The University of Sydney, NSW 2006, Australia. 